\title{
ANALISIS TINGKAT BERPIKIR DALAM MENYELESAIKAN SOAL GERAK PARABOLA MENGGUNAKAN TAKSONOMI STRUCTURE OF THE OBSERVED LEARNING OUTCOMES (SOLO) SISWA KELAS X MIA SMAN 1 SUNGAI RAYA
}

\author{
1Desi Hartanti, ${ }^{T}$ Tomo Djudin, ${ }^{3}$ Syukran Mursyid \\ 1,2,3 Prodi Pendidikan Fisika, Universitas Tanjungpura, Kota Pontianak, Indonesia \\ *Email Korespondensi: desihartanti1705@gmail.com
}

\section{INFO ARTIKEL}

\section{Diterima}

02 Desember 2020

Direvisi

Dipublikasikan : 31 Januari 2021

\section{ABSTRACT}

\begin{abstract}
This This study aims to describe the level of students' thinking profile in solving parabolic motion problems based on the SOLO taxonomy seen from learning outcomes and gender. This is a survey research without a comparison group. Data collection was done by giving 4 questions to 95 class X MIA students at SMAN 1 Sungai Raya, and categorized based on learning outcomes (high, medium, low) and gender (male, female). The level of students' thinking profile in solving parabolic motion problems based on SOLO taxonomy is $50.52 \%$ at the pre-structural level, $11.57 \%$ at the uni-structural level, $21.05 \%$ at the multi-structural level, $16.84 \%$ at relational level, and $0 \%$ at extendedabstract level. Additionally, students with high learning outcomes reached the unistructural-relational thinking level, while moderate ones reached the uni-structural-multistructural level, and low ones reached the uni-structural-pre-structural level. In terms of gender, female students' average percentage of thinking level is $44.2 \%$ higher than male students with only $33.6 \%$ of the ideal score.
\end{abstract}

Keywords: Thinking Level, SOLO Taxonomy, Parabolic Motion.

\section{Pendahuluan}

Memasuki abad ke-21 setiap orang perlu menguasai keterampilan berpikir kritis dan pemecahan masalah sebagai alternatif upaya pemenuhan kebutuhan hidup yang lebih berbasis pada pengetahuan (Redhana W, 2019). Pengembangan keterampilan abad ke-21 ini dapat dilakukan pada fisika sebagai salah satu disiplin IPA. Pemahaman konsep dan keterampilan mengaplikasikan konsep ke dalam permasalahan fisika sangat diperlukan dalam mengembangkan keterampilan abad ke-21. Salah satu materi fisika yang memerlukan pemahaman konsep yang mendasar dalam menyelesaikan soal yaitu materi kinematika gerak tentang gerak parabola. Gerak Parabola dikategorikan sebagai materi fisika yang mengandung kompetensi dasar dengan kata kerja operasional "menganalisis", maka pembelajaran gerak parabola hendaknya dilaksanakan melalui proses pemecahan masalah (BSNP, 2006).

Hasil survei Programme for International Student Assessment (PISA) tahun 2015 menunjukkan performa siswa Indonesia dalam bidang sains. Berdasarkan hasil PISA 2015, rata-rata skor yang dicapai siswa Indonesia pada bidang sains, membaca, dan matematika menduduki peringkat 62, 61, dan 63 dari 69 negara yang dievaluasi. Apabila ditinjau meskipun mengalami peningkatan, hasil tes dan survei PISA 2015 tidak berbeda jauh dengan hasil tes dan survei PISA terdahulu pada tahun 2012 yang tergolong pada kelompok penguasaan materi yang rendah (Iswadi, 2016). PISA membagi capaian kemampuan literasi siswa dalam enam tingkatan (level). Level tersebut menggambarkan tingkat penalaran dalam menyelesaikan masalah. Mayoritas siswa di Indonesia belum mencapai level 2 untuk matematika $(75,7 \%)$ dan sains $(66,6 \%)$ dan lebih mirisnya lagi 42,3\% siswa belum mampu mencapai level kecakapan terendah (level 1) untuk matematika dan sejumlah 24,7\% untuk sains (OECD, 2013). Hasil capaian tersebut mengindikasikan bahwa masih banyak siswa Indonesia yang belum 
memiliki kemampuan untuk algoritma, rumus dan prosedur dasar untuk memecahkan soal (Indonesia PISA Centre, 2014).

Kemampuan siswa dalam memecahkan soal dapat dinilai dengan menggunakan taksonomi Structure of the Observed Learning Outcomes (SOLO) yang dikembangkan oleh Biggs dan Collis pada tahun 1982. Biggs dan Collis mengklasifikasikan taksonomi SOLO ke dalam 5 level yaitu pre-structural, uni-structural, multi-structural, relational, dan extended-abstract (Biggs dan Tang, 2007). Kelima tingkatan tersebut digambarkan sebagai berikut:

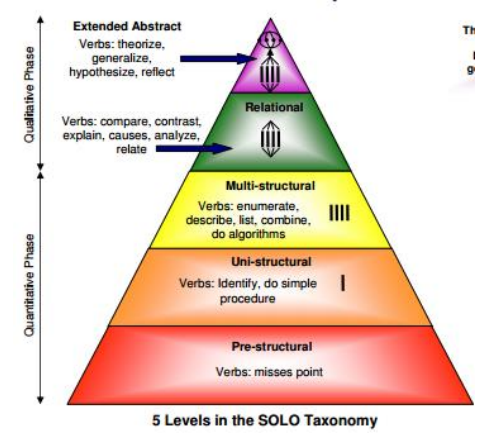

\section{Gambar 1. Level dalam taksonomi SOLO}

Pada level pre-structural, siswa tidak tahu sama sekali apa yang seharusnya dipelajari, tidak tahu cara mengumpulkan informasi (Potter dan Kustra, 2012: 10), siswa tidak tahu cara menghubungkan konsep satu dengan lainnya, bahkan tidak tahu sama sekali konsep untuk penyelesaian masalah. Level uni-structural, siswa dapat menggunakan satu informasi yang tersedia di dalam soal. Siswa yang berada pada level ini diindikasikan dengan memiliki kemampuan dalam menggunakan terminologi, mengingat kembali, menggunakan instruksi/algoritma sederhana, menafsirkan, mengidentifikasi, memberi nama, menghitung (O'Neill dan Murphy, 2010; Braband dan Dahl, 2009). Pada level multi-structural Siswa telah memahami semua konsep secara keseluruhan serta dapat membuat hubungan antara sejumlah konsep tetapi gagasan utuh dari materi belum dapat dipahami dengan jelas. Level ini ditandai dengan kemampuan siswa dalam menggambarkan, mengklasifikasikan, mengkombinasikan, melakukan algoritma, mengaplikasikan metode (Braband, Dahl, 2009). Sementara itu pada level relational Siswa dapat mengintegrasikan seluruh konsep sehingga menghasilkan gambaran menyeluruh mengenai yang telah dipelajari. Siswa yang berada pada level ini diindikasikan dengan memiliki kemampuan dalam menganalisis, membandingkan, mengintegrasi, menghubungkan, menjelaskan sebab-akibat, mengaplikasikan teori (Braband dan Dahl, 2009). Level tertinggi yaitu extended-abstract, pada level ini siswa dapat menggunakan pengetahuan yang telah dipelajari untuk memecahkan masalah tidak hanya di dalam soal tetapi juga masalah di kehidupannya. Siswa yang tergolong pada level ini diindikasikan dengan memiliki kemampuan dalam menggeneralisasikan, berhipotesis, memprediksi, mengkritik, menilai (Braband dan Dahl, 2009).

Tentunya sudah banyak riset yang mengkaji tentang taksonomi SOLO. Azizah (2012) menerapkan taksonomi SOLO untuk mengetahui tingkat respon siswa kelas XI dalam menyelesaikan soal Ujian Akhir Semester Gasal pada mata pelajaran fisika. Sementara Annisa Rahman (2014) menggunakan taksonomi SOLO untuk mengetahui persentase jumlah siswa kelas $X$ yang tidak mampu memecahkan soal tentang konsep hukum Archimedes di SMA Negeri 8 Pontianak. Berdasarkan temuan-temuan tersebut dapat diketahui bahwa taksonomi SOLO dapat digunakan sebagai alat yang mudah dan sederhana untuk menyusun dan menentukan tingkat kesulitan (kompleksitas) suatu pertanyaan di dalam soal. Tahapan siswa dalam menyelesaikan soal tentu melibatkan proses berpikir dari level yang paling dasar hingga level yang kompleks.

Taksonomi berpikir yang terkenal adalah taksonomi Bloom. Crowe \& Wenderoth; Zheng, 2008 (dalam Sucipto, 2017) mengemukakan taksonomi Bloom revisi pada dasarnya terdiri dari kemampuan berpikir tingkat rendah untuk mengingat dan memahami ke tingkat yang lebih kompleks dalam mengevaluasi dan menciptakan pengetahuan baru. Meskipun taksonomi Bloom yang direvisi bertindak sebagai taksonomi kognitif dalam desain silabus sekolah menengah di Indonesia serta telah banyak digunakan dalam penilaian pendidikan sains, namun taksonomi Bloom tidak disertai dengan kriteria untuk menilai hasil pembelajaran yang memungkinkan umpan balik, hirarkis dan eksplisit terutama dalam penilaian soal essay. Berbeda dengan taksonomi SOLO yang lebih spesifik dalam mengklasifikasikan cara berpikir siswa yang dapat dilihat dari respon siswa ketika memberikan 
perlakuan untuk membaca dan menjawab pertanyaan soal. Maka dalam penelitian ini, peneliti menekankan pada menilai hasil belajar melalui tes menyelesaiakan soal tentang gerak parabola secara sistematis menggunakan taksonomi SOLO yang menelusuri pengetahuan siswa dari tingkat sederhana/permukaan (surface knowledge) ke konstruksi pemahaman yang lebih dalam (constructed/deep knowledge).

Taksonomi SOLO tidak hanya dapat digunakan sebagai alat untuk menilai hasil belajar siswa, tetapi juga dapat digunakan sebagai panduan dalam merancang rencana pembelajaran serta perangkat evaluasi untuk meningkatkan kemampuan siswa terhadap suatu konsep (Biggs dan Tang, 2007). Dengan mengetahui tingkat kemampuan berpikir siswa dalam memecahkan soal berdasarkan taksonomi SOLO maka pemebelajaran fisika akan menjadi lebih efektif dan mendukung siswa untuk mencapai kompetensi yang telah ditentukan. Penelitian ini dilakukan di SMAN 1 Sungai Raya dengan pertimbangan rata-rata nilai ulangan harian pada materi gerak parabola masih tergolong rendah yaitu 66,1 serta karakteristik siswa SMAN 1 Sungai Raya yang beragam sehingga memungkinkan setiap siswa memiliki kemampuan berpikir yang beragam pula. Dengan adanya karakteristik siswa SMAN 1 Sungai Raya yang bersifat heterogen, maka hal tersebut memungkinkan pula terjadinya perbedaan tingkat berpikir dalam hal kemampuan memecahkan persoalan fisika karena berbeda gender, etnik, dan usia. George Romanes (1887) menyatakan bahwa gender mempengaruhi ukuran otak sehingga berpengaruh pula pada kemampuan siswa dalam menerima pelajaran. Meta-analisis yang dilakukan oleh Hyde dan Mertz (2009) terhadap 100 penelitian yang mewakili lebih dari 3 juta siswa pada jenjang pendidikan SMA di Amerika, Kanada, dan Australia untuk mengetahui besar pengaruh perbedaan gender, etnik dan umur pada kemampuan matematika sehingga memperoleh effect size sebesar 0,03-0,26 dengan kemampuan matematika siswa laki-laki lebih unggul dibanding siswa perempuan.

Masalah penelitian yang pertama menunjukkan profil tingkat berpikir siswa dalam menyelesaikan soal gerak parabola di 5 level taksonomi SOLO. Melalui profil ini, peneliti mengidentifikasi kemampuan berpikir siswa dalam memecahkan masalah sesuai prosedur Polya yang disesuaikan dengan kriteria respon terhadap soal dalam taksonomi SOLO. Masalah kedua membahas adakah ditemukan perbedaan tingkat berpikir dalam menyelesaikan soal gerak parabola berdasarkan hasil belajar siswa (tinggi, sedang, dan rendah). Sejalan dengan penelitian U. H. Putri, dkk (2017) yang menunjukkan adanya perbedaan performa berpikir dalam menyelesaikan soal berdasarkan taksonomi SOLO. Terakhir, masalah ketiga membahas mengenai perbedaan tingkat berpikir dalam menyelesaikan soal gerak parabola berdasarkan gender. Penelitian terdahulu memperoleh temuan bahwa terdapat perbedaan skor kognitif siswa berdasarkan gender yang telah diuji melalui tes kognitif pada kinerja visual-spasial (dalam Ormord, 2008: 177), matematika (Zhu, 2007), dan beberapa penilaian pemahaman konsep fisika (Miyake dkk, 2010; Madsen dkk, 2013). Peneliti beranggapan bahwa kesenjangan oleh gender mungkin saja terdapat dalam tingkat berpikir siswa.

\section{Metode Penelitian}

Penelitian ini dilakukan untuk mengidentifikasi tingkat berpikir siswa menggunakan taksonomi SOLO dalam menyelesaikan soal gerak parabola dan bagaimana hubungannya berdasarkan gender dan hasil belajar. Jenis penelitian yang sesuai adalah penelitian survei tanpa kelompok pembanding yang bersifat deskriptif korelatif karena dalam penelitian ini menganalisis hubungan antara satu keadaan dengan keadaan lainnya, yaitu hubungan antara tingkat berpikir siswa dengan gender dan hasil belajar.

Siswa kelas X MIA SMAN 1 Sungai Raya tahun ajaran 2019/2020 berjumlah 130 orang. Ditetapkan 95 orang siswa sebagai sampel penelitian berdasarkan tabel penentuan sampel yang dikembangkan oleh Isaac dan Michael dengan taraf signifikansi 5\% (Sugiyono, 2013: 69-71). Sebanyak 56 siswa perempuan dan 39 siswa lakilaki dari kelas X MIA 1, X MIA 2, X MIA 3, dan X MIA 5 terlibat dalam penelitian yang ditetapkan dengan teknik proportional sampling (Hadi, 2000: 187; Sugiyono, 2010: 73; Dharma, 2011: 14). Alat pengumpul data menggunakan 4 buah soal uraian mengenai konsep gerak parabola : jarak, waktu, dan kecepatan pada gerak parabola di sembarang titik, pada titik tertinggi dan pada titik terjauh serta besar sudut elevasi pada gerak parabola. Reliabilitas tes tingkat berpikir dihitung menggunakan aplikasi SPSS 25.0 dengan melihat hasil output reliabilitas tes pada kolom Cronbach's Alpha.

Data jawaban siswa dianalisis dengan memberikan skor 0-16 berpedoman pada rubrik penskoran yang telah dibuat. Masing-masing skor mencerminkan kualitas berpikir dalam menyelesaikan soal gerak parabola berdasarkan level dalam taksonomi SOLO . Kemudian, persentase tingkat berpikir ditentukan dengan membagi skor yang diperoleh siswa dari hasil penelitian dengan skor ideal yaitu skor yang ditetapkan jika pada setiap 
pertanyaan siswa menjawab dengan skor tertinggi pada tiap level SOLO. Selanjutnya digunakan uji One-Way Anova dan uji lanjut Scheffe-test (data berdistribusi normal dan homogen) menggunakan SPSS 25.0 untuk menjawab masalah kedua yaitu apakah terdapat perbedaan kemampuan berpikir siswa dalam menyelesaikan soal gerak parabola berdasarkan hasil belajar. Selanjutnya untuk menjawab masalah ketiga, yaiu apakah terdapat perebedaan tingkat berpikir siswa dalam menyelesaikan soal gerak parabola berdasarkan gender, dijawab menggunakan uji statistik U Mann-Whitney (data berdistribusi normal tetapi tidak homogen) dengan aplikasi SPSS 25.0.

\section{Hasil dan Pembahasan}

3.1 Hasil

Tingkat berpikir siswa yang diselidiki dalam penelitian ini adalah kemampuan siswa dalam menyelesaikan soal gerak parabola pada setiap level taksonomi SOLO; uni-structural, multi-structural, relational, dan extended-abstract. Jawaban siswa yang telah dianalisis dibuat profil tingkat berpikir yang disajikan pada Tabel 1.

Tabel 1. Profil Tingkat Berpikir Siswa Berdasarkan Taksonomi SOLO

\begin{tabular}{lcccc}
\hline $\begin{array}{c}\text { Level Taksonomi } \\
\text { SOLO }\end{array}$ & No Soal & $\begin{array}{c}\text { Jumlah Siswa yang } \\
\text { memperoleh skor pada } \\
\text { level }\end{array}$ & $\begin{array}{c}\text { Skor yang } \\
\text { diperoleh siswa / } \\
\text { Skor ideal }\end{array}$ & $\begin{array}{c}\text { Tingkat Berpikir } \\
\text { (\%) }\end{array}$ \\
\hline Uni-structural & $1-4(\mathrm{a})$ & 294 & $294 / 760$ & $38,6 \%$ \\
\hline Multi-structural & $1-4(\mathrm{~b})$ & 2377 & $2377 / 4560$ & $52,1 \%$ \\
\hline Relational & $1-4(\mathrm{c})$ & 2459 & $2459 / 5320$ & $46,2 \%$ \\
\hline Extended-abstract & $1-4(\mathrm{~d})$ & 389 & $389 / 6080$ & $6,3 \%$ \\
\hline
\end{tabular}

Hasil uji One-Way Anova dengan menggunakan aplikasi SPSS 25.0 untuk menjawab hipotesis komparatif mengenai apakah terdapat perbedaan tingkat berpikir siswa kelas X MIA SMAN 1 Sungai Raya berdasarkan hasil belajar (tinggi, sedang, rendah ditunjukkan oleh Tabel 2 berikut.

Tabel 2. Hasil Uji One-Way Anova Tingkat Berpikir Siswa Berdasarkan Hasil Belajar

\begin{tabular}{|l|r|r|r|r|r|}
\hline \multicolumn{7}{|l|}{ ANOVA } \\
\hline Nilai_tes & Sum of Squares & Df & Mean Square & F & Sig. \\
\hline & 2087,787 & 2 & 1043,894 & 5,495 &, 006 \\
\hline Between Groups & 17478,950 & 92 & 189,989 & & \\
\hline Within Groups & 19566,737 & 94 & & & \\
\hline Total & 94 & & & \\
\hline
\end{tabular}

Hal ini juga secara spesifik didukung oleh hasil uji lanjut (Post Hoc Analysis) -Scheffe-test dengan melihat perbandingan berpasangan antar kelompok belajar, yang ditunjukkan seperti Tabel 3 berikut.

Tabel 3. Hasil Uji Post-Hoc (Scheffe-test) SPSS 25.0 untuk Hasil Belajar

\begin{tabular}{|c|c|c|c|c|c|c|}
\hline \multicolumn{7}{|c|}{ Multiple Comparisons } \\
\hline \multicolumn{7}{|c|}{$\begin{array}{l}\text { Dependent Variable: nilai tes } \\
\text { Scheffe }\end{array}$} \\
\hline (I) hasil belajar & (J) hasil belajar & $\begin{array}{c}\text { Mean Difference } \\
(\mid-J)\end{array}$ & Std. Error & Sig. & $\begin{array}{l}\text { 95\% Confid } \\
\text { Lower Bound }\end{array}$ & $\begin{array}{l}\text { nce Interval } \\
\text { Upper Bound }\end{array}$ \\
\hline \multirow[t]{2}{*}{ Tinggi } & Sedang & 1,670 & 3,344 &, 883 & $-6,65$ & 9,99 \\
\hline & Rendah & $11,135^{*}$ & 3,577 & 010 & 2,23 & 20,03 \\
\hline \multirow[t]{2}{*}{ Sedang } & Tinggi & $-1,670$ & 3,344 & 883 & $-9,99$ & 6,65 \\
\hline & Rendah & $9,465^{*}$ & 3,531 & 031 & 68 & 18,25 \\
\hline \multirow[t]{2}{*}{ Rendah } & Tinggi & $-11,135^{*}$ & 3,577 & ,010 & $-20,03$ & $-2,23$ \\
\hline & Sedang & $-9,465^{*}$ & 3,531 & ,031 & $-18,25$ &,- 68 \\
\hline
\end{tabular}


Hasil uji U Mann-Whitney untuk menjawab hipotesis komparatif mengenai apakah terdapat perbedaan tingkat berpikir dalam menyelesaikan soal gerak parabola antara kelompok siswa laki-laki dan perempuan ditunjukkan pada tabel 4.

Tabel 4. Hasil Uji U Mann-Whitney Tingkat Berpikir Siswa Berdasarkan Gender

\begin{tabular}{|lr|}
\hline & Nilai_Tes \\
\hline Mann-Whitney U & 804,500 \\
\hline Wilcoxon W & 1584,500 \\
\hline Z & $-2,176$ \\
\hline Asymp. Sig. (2-tailed) &, 030 \\
\hline a. Grouping Variable: Gender & \\
\hline
\end{tabular}

\subsection{Pembahasan}

Hasil analisis data untuk mengetahui profil tingkat berpikir siswa dalam menyelesaikan soal gerak parabola berdasarkan taksonomi SOLO yang ditunjukkan pada Tabel 1 diperoleh rata-rata 35,8\%. Hasil tersebut tergolong dalam kategori rendah. Selanjutnya disajikan profil tingkat berpikir siswa berdasarkan hasil analisis pengkategorian level seperti yang ditunjukkan oleh Gambar 2 berikut.

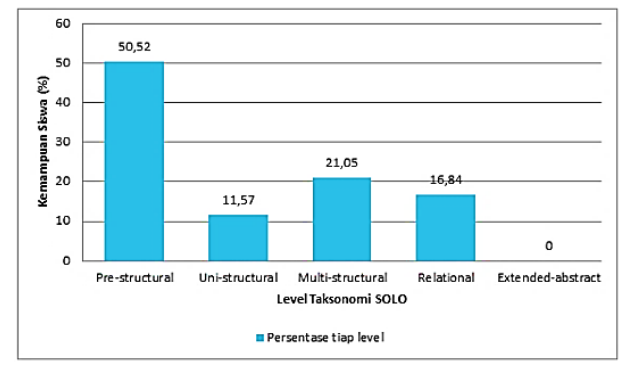

\section{Gambar 2 Diagram Profil Kemampuan Siswa dalam Menyelesaiakan Soal Berdasarkan Taksonomi SOLO}

Berdasarkan Gambar 2 dapat diketahui persentase siswa yang masuk dalam kategori level Prestructural sebesar 50,52\%. Tingginya persentase pada level ini menunjukkan bahwa setengah/separuh siswa kelas X MIA SMAN 1 Sungai Raya masih berada pada level pre-structural. Siswa pada level prestructural masih belum dapat menggunakan data/informasi yang diperoleh dari soal dan tidak memahami sama sekali masalah yang harus dipecahkan. Dalam penelitian ini siswa digolongkan dalam level prestructural yakni siswa yang tidak memberikan respon sama sekali terhadap soal atau respon yang diberikan itu keliru (tidak ada kaitannya dengan soal/misses the point). Respon pada level pre-structural biasanya dituliskan menggunakan tautologi untuk menutupi kurangnya pengetahuan/pemahaman (Biggs dan Tang, 2007).

Pada level uni-structural diperoleh persentase sebesar 11,57\% menunjukkan masih rendahnya tingkat berpikir siswa dalam mengerjakan soal pada level terendah. Siswa uni-structural secara umum mampu menyelesaikan soal menggunakan sebuah informasi yang jelas untuk mendapatkan penyelesaian akhir. Secara keseluruhan, kemampuan siswa dalam menyelesaikan soal gerak parabola (level uni-structural) pada penelitian ini tampak bervariasi dan tidak konsisten terhadap cara penyelesaian meskipun semua soal menyentuh aspek kognitif yang sama yaitu mengidentifikasi dan menjelaskan (level C1 dan C2 dalam taksonomi Bloom). Level multi-structural diperoleh persentase sebesar 21,05\%. Persentase demikian menggambarkan beberapa siswa sudah mampu melakukan operasi algoritma sederhana dalam memecahkan soal gerak parabola. Siswa yang termasuk dalam kategori level ini dapat membuat bebrapa hubungan data/informasi dalam memecahkan masalah. Persentase siswa level relational diperoleh sebesar 
16,84\% menunjukkan bahwa siswa dapat merespon suatu tugas berdasarkan konsep-konsep yang terintegrasi dan dapat menghubungkan semua informasi yang ada secara relevan, sehingga konklusi yang diperoleh selalu konsisten terhadap konsep yang ada. Pada level extended-abstract diperoleh persentase 0\%. Rendahnya persentase ini disebabkan oleh ketidakmampuan siswa dalam memahami struktur pengetahuan dari berbagai perspektif yang mengaitkan konsep gerak parabola dengan konsep fisika lainnya. Pada level extended-abstract siswa sudah dapat membuat generalisasi suatu pengetahuan dengan pengalaman lain.

Berdasarkan Tabel 2 diketahui bahwa nilai F hitung > F Tabel (5,495 > 3,095). Dengan demikian dapat diambil kesimpulan bahwa terdapat perbedaan tingkat berpikir antara kelompok siswa dengan hasil belajar tinggi, sedang, dan rendah. Sejalan dengan penelitian terdahulu oleh U.H. Putri, dkk (2017) yang menemukan adanya perbedaan performa berpikir dalam menyelesaikan soal berdasarkan taksonomi SOLO untuk kategori siswa HSE (High Self Eficiacy), MSE (Medium Self Eficiacy), dan LSE (Low Self Eficiacy). Dalam penelitian ini, siswa kategori Hasil Belajar Tinggi (HBT) mampu menyelesaikan soal dari mampu level terendah (uni-structural) sampai ke level relational. Siswa dengan kategori HBT dapat menggunakan dan menghubungkan dua atau lebih informasi sesuai dengan masalah yang diberikan. Sementara siswa kategori Hasil Belajar Sedang (HBS) mampu mencapai level multi-structural, dan siswa kategori Hasil Belajar Rendah (HBR) hanya mampu menyelesaikan masalah pada level terendah (uni-structural), bahkan tidak mampu sama sekali menyelesaikan masalah atau menggunakan informasi tetapi tidak relevan (level pre-structural. Meskipun hasil uji One-Way Anova menunjukkan adanya perbedaan yang signifikan, namun tidak ditemukan perbedaan performa proses berpikir dalam memecahkan masalah yang mencolok antara kelompok hasil belajar tinggi, sedang, dan rendah. Secara umum, ketiga kelompok mengalami kesulitan pada level extended-abstract dan konsep gerak parabola yang sama dengan bentuk kekeliruan yang juga sama.

Secara lebih spesifik hal tersebut didukung oleh hasil Scheffe-test pada Tabel 3 dapat diketahui bahwa untuk kelompok hasil belajar tinggi vs. sedang menunjukkan nilai sig. $(0,883)>0,05$. Hal ini berarti tidak terdapat perbedaan tingkat berpikir yang signifikan dalam menyelesaikan soal gerak parabola antara siswa kelompok hasil belajar tinggi dan sedang. Sedangkan hasil uji untuk kategori tinggi vs. rendah diperoleh nilai sig. $(0,010)<0,05$, hal ini mengindikasikan bahwa memang terdapat perbedaan yang signifikan antara siswa kelompok hasil belajar tinggi dengan siswa hasil belajar rendah. Untuk kategori sedang vs. rendah nilai sig. sebesar 0,031<0,05. Dengan demikian, nilai tersebut menunjukkan adanya perbedaan tingkat berpikir yang signifikan dalam menyelesaikan soal gerak parabola antara siswa kelompok hasil belajar sedang dan rendah.

Beberapa penelitian menemukan perbedaan kemampuan kognitif siswa dalam keterampilan visualspasial, verbal, dan matematika antara siswa laki-laki dan perempuan. Namun, perbedaan tersebut cenderung teramat kecil, dengan ketumpang-tindihan yang banyak diantara kedua gender (Ormord, 2008: 177, Santrock, 2007: 229). Acapkali, sejumlah penelitian menemukan hal-hal yang mengejutkan. Sebagai halnya penelitian yang dilakukan Allan dkk pada tahun 1996 yang menganalisis gambar volumetrik otak beresolusi tinggi dengan temuan volume total otak anak laki-laki 10\% > dari anak perempuan, lebih lanjut ditemukan interelasi positif antara volume total otak dengan IQ seseorang (Allan dkk, 1996: 1763-1774). Hal ini bermakna bahwa anak laki-laki mempunyai IQ lebih tinggi dibanding anak perempuan. Meskipun demikian, Dezolt \& Hull, 2001 (dalam Santrock, 2007: 230) menemukan bahwa siswa laki-laki sering masuk dalam kelas remedial dibanding siswa perempuan.

Penelitian ini menemukan rata-rata skor tingkat berpikir dalam menyelesaikan soal gerak parabola siswa perempuan (mencapai 44,2\% dari skor ideal) lebih tinggi dari siswa laki-laki (mencapai 36,6\% dari skor ideal), bertentangan dengan penelitian terdahulu dalam sejumlah tes kognitif dan kaitannya dengan gender (Miyake dkk, 2010; Madsen, McKagan, Sayre dan Eleanor, 2013; C. D. Wright dkk, 2016). 
Berdasarkan temuan penelitian ini maupun penelitian terdahulu yang dipaparkan di depan, kita mengetahui bahwa perebedaan gender cenderung tidak pasti, tidak konsisten, dan tidak dapat digeneralisasikan. Sebagian kasus menemukan jenis kelamin tertentu unggul pada suatu bidang, namun di lain kesempatan dengan persoalan yang berhubungan justru mendapati hasil yang bertentangan. Sehingga adanya perbedaan kemampuan yang ditemukan dalam penelitian ini diharapkan tidak menjadi bahan justifikasi dengan menganggap perempuan lebih unggul dari laki-laki, atau sebaliknya.

Meskipun penelitian ini tidak secara spesifik meneliti faktor pendukung yang menyebabkan terjadinya perbedaan dengan skor siswa perempuanlebih tinggi dari laki-laki, namun dari pengamatan peneliti menemukan beberapa kemungkinan. Pertama, perilaku di kelas dan motivasi akademis siswa perempuan lebih baik daripada siswa laki-laki selama tes. Siswa perempuan lebih peduli dan serius dalam mengerjakan soal tes, lebih banyak bertanya ketika menemukan soal-soal tes yang kurang jelas. Sebaliknya siswa laki-laki cenderung bermain di kelas dan menjawab yang tidak berkaitan dengan soal tes. Alasan kedua, rata-rata hasil belajar siswa perempuan lebih tinggi daripada siswa laki-laki berdasarkan daftar nilai ulangan harian siswa kelas X MIA SMAN 1 Sungai Raya tahun ajaran 2019/2020. Artinya, pencapaian akademik siswa perempuan lebih baik dari siswa laki-laki. Tes kemampuan akademik (khususnya pada ranah kognitif) di sekolah untuk pelajaran fisika seringkali mengimplikasikan kemampuan siswa dalam menyelesaikan masalah. Seperti yang diketahui bahwa proses memecahkan masalah fisika melibatkan proses/tahap berpikir. Dengan demikian hasil belajar siswa perempuan yang lebih tinggi dari siswa laki-laki dimungkinkan mempengaruhi perbedaan skor pencapaian tingkat berpikir siswa perempuan dan laki-laki pada penelitian ini. Bagaimanapun, mungkin terdapat faktor lain yang tidak terjangkau oleh peneliti yang menjadi keterbatasan penelitian ini.

\section{Kesimpulan}

Berdasarkan hasil penelitian, secara umum dapat disimpulkan bahwa tingkat berpikir siswa kelas X MIA SMAN 1 Sungai Raya dalam menyelesaikan soal gerak parabola yang dianalisis menggunakan taksonomi SOLO masih tergolong rendah dengan persentase pencapaian sebesar 35,8\% dari skor ideal penyelesaian soal tingkat berpikir. Secara khusus hasil penelitian disimpulkan sebagai berikut:

(1) Penelitian ini menemukan profil tingkat berpikir siswa dalam menyelesaikan soal gerak parabola pada setiap level taksonomi SOLO diantaranya: (a) level uni-structural sebesar 38,6\% dari skor ideal, (b) level multi-structural sebesar 52,1\% dari skor ideal, (c) level relational sebesar 46,2\% dari skor ideal, dan (d) level extended-abstract sebesar 6,3\% dari skor ideal. Sementara itu, profil tingkat berpikir siswa dalam menyelesaikan soal ditinjau dari analisis pengkategorian sesuai kriteria respon taksonomi SOLO sebagai berikut: (a) level pre-structural sebesar 50,52\%, (b) level uni-structural sebesar 11,57\%, (c) level multistructural sebesar 21,05\%, (d) level relational sebesar 16,84\%, dan (e) level extended-abstract sebesar 0\%.

(2) Terdapat perbedaan tingkat berpikir dalam menyelesaikan soal gerak parabola berdasarkan taksonomi SOLO antara kelompok siswa dengan hasil belajar tinggi, sedang, dan rendah ( $p>0,05, F_{0} 5,495>F_{\text {tabel }}$ 3,095). Lebih spesifik hasil uji perbandingan berpasangan Scheffe-test menunjukkan tidak ada perbedaan tingkat berpikir yang signifikan antara siswa kelompok hasil belajar "Tinggi vs. Sedang" (sig. (0,883 > 0,05). Sedangkan untuk kategori "Tinggi vs. Rendah" dan "Sedang vs. Rendah" terdapat perbedaan tingkat berpikir yang signifikan antara kedua kelompok hasil belajar tersebut dengan masing-masing nilai sig. sebesar 0,010 dan 0,031<0,05.

(3) Terdapat perbedaan tingkat berpikir dalam menyelesaikan soal gerak parabola berdasarkan taksonomi SOLO antara kelompok siswa laki-laki dan perempuan ( $p>0,05$, Asymp. Sig. (2-tailed) $=0,030<$ probabilitas $=0,05$. 


\section{Referensi}

Allan. dkk. (1996). Brain Development, Gender and IQ children : A Volumetric Imaging Study. Oxford University. Brain (1996), 119, 1763-1774.

Annisa Rahman. (2014). Ketidakmampuan Pemecahan Soal Hukum Archimedes Berdasarkan Taksonomi Structure of the Observed Learning Outcomes Siswa SMA. Jurnal Pendidikan dan Pembelajaran. Vol. 3, No 7.

Azizah (2012). Evaluasi Hasil Belajar Berdasarkan Taksonomi SOLO. (Online). (http://eprints.walisongo.ac.id/968/4/083611020_Bab2.pdf, diakses pada 2 Oktober 2018).

Biggs, J. \& Tang, C. (2007). Teaching for Quality Learning at University. (Online). (http://store.freecollege.org/noleech1.php?hidden=q:/386000/45cc90a412ef1783ee6d3e10cbaecb59\&hidden0=John+Bigg $\mathrm{s},+$ Catherine+Tang+Teaching+for+Quality+Learning+at+University+++2007.pdf, diakses pada 2 Oktober 2018)

Braband, C. dan Dahl, B. (2009). Using the SOLO taxonomy to analyze competence progression of university science curricula. Journal Higher Education, Vol 58, No.4: 531-549. (http://www.itu.dk/ brabrand/progression.pdf, diakses pada tanggal 2 Oktober 2018).

C.D. Wright, dkk. (2016). Cognitive Difficulty and Format Gender and Sosioeconomic Gaps in Exam Performance of Student in Introdutory Biology Courses. CBE - life science education Vol.15, 1-16, summer 2016.

Dharma, Kusuma Kelana (2011). Metodologi Penelitian Keperawatan : Panduan Melaksanakan dan Menerapkan Hasil Penelitian. Jakarta: Trans InfoMedia.

Hadi, Sutrisno. 2000. Metodologi Penelitian. Yogyakarta: Andi Yogyakarta.

Hyde, J. S \& dan Mertz, J.E. (2009). Gender, Culture and Mathematics Performances. (Online). (http://www.pnas.org/content/106/22/8801.full.pdf, diakses pada tanggal 2 Oktober 2018).

Indonesia PISA Centre. (2014). Level PISA. (Online). (http://www.indonesiapisacenter.com /2013/08/levelpisa.html, diakses pada tanggal 2 Oktober 2018).

Iswadi, Hazrul. (2016). Sekelumit Dari Hasil PISA 2015 Yang Baru Dirilis. (Online). (http://www.ubaya.ac.id/2014/content/articles_detail/230/Overview-of-the-PISA-2015-results-that-havejust-been-Released.html, diakses pada tanggal 2 Oktober 2018).

Madsen, McKagan, Sarah B., \& Sayre, Eleanor C. (2013). Gender Gap on Concept Inventories in Physics: What is Consistent, and What Factors Influence Gap. Physical Review Special Topics - Physics Education Research 9,020121.

O'Neill, G. \& Murphy, F. (2010). UCD Teaching and Learning/Resources, Guide to Taxonomy of Learning. (http://www.ucd.ie/t4cms/ucdtla0034.pdf, diunduh pada tanggal 2 Oktober 2018).

OECD. (2013). PISA 2012 Assessment and Analytical Framework: Mathematics, Reading, Science, Problem Solving and Financial Literacy. Paris: OECD Publishing.

Ormord, Jeanne Ellis. (2008). Psikologi Pendidikan Jilid I. Jakarta: Erlangga.

Potter, M.K \&Kustra, E. (2012). Primer on Learning Outcomes and SOLO Taxonomy. (http://www.uwindsor.ca/ctl/system/files/PRIMER-on-Learning-Outcomes.pdf, diunduh pada tanggal 2 Oktober 2018)

Putri, H. U, dkk. (2017). How to Analyze the Students' Thinking Levels Based on SOLO Taxonomy?. Journal of Physics: Conference Series.

Redhana, W.I. (2019). Mengembangkan Keterampilan Abad Ke-21 Dalam Pembelajaran Kimia. Jurnal Inovasi Pendidikan Kimia Vol 13, No 1:2239-2253.

Santrock, John W. (2007). Remaja Edisi II Jilid l; (Penerjemah: Benedictine Widyasinta). Jakarta: Erlangga.

Sucipto, (2017). Pengembangan Keterampilan Berpikir Tingkat Tinggi Dengan Menggunakan Strategi Metakognitif Model Pembelajaran Problem Based Learning. Jurnal Pendidikan Vol. 2, No 1: 64 - 65. 
Sugiyono. (2013). Metode Penelitian Kuantitatif Kualitatif dan R\&D. Bandung: Alfabeta.

Zhu, Zheng. (2007). Gender Differences in Mathematical Problem Solving Patterns: A riview of literature. International Education Journal, 2007, 8(2), 187-203. 